\title{
Bactericidal Effect of a Novel Alkaline EDTA Root Canal Cleaning Solution
}

\author{
Takenori Sato ${ }^{1}$ Ryuji Fujimaki ${ }^{2}$ jiro Suzuki ${ }^{2}$ Nobushiro Hamada ${ }^{3}$ Nobuyuki Tani-Ishii ${ }^{2}$ \\ Keisuke Handa ${ }^{1}$
}

${ }^{1}$ Department of Oral Science, Division of Oral Biochemistry, Graduate School of Dentistry, Kanagawa Dental University, Kanagawa, Japan

2Department of Oral Interdisciplinary Medicine, Division of Pulp Biology, Graduate School of Dentistry, Kanagawa Dental University, Kanagawa, Japan

${ }^{3}$ Department of Oral Science, Division of Microbiology, Graduate School of Dentistry, Kanagawa Dental University, Kanagawa, Japan

Eur J Dent 2021;15:546-550
Address for correspondence Keisuke Handa, DDS, PhD, Department of Oral Science, Division of Oral Biochemistry, Graduate School of Dentistry, Kanagawa Dental University, 82 Inaoka-cho, Yokosuka, Kanagawa 239-8580, Japan (e-mail: handa@kdu.ac.jp).

\author{
Abstract \\ Keywords \\ - ethylenedi- \\ aminetetraacetic acid \\ - sodium hypochlorite \\ - biofilm \\ - root canal irrigant
}

Objectives In this study, we aimed to evaluate the bactericidal effect and cytotoxicity of an ethylenediaminetetra-acetic acid (EDTA)-based root canal irrigant solution capable of efficiently removing both the organic matter and the smear layer. We prepared a strong alkaline EDTA (AE) solution with an acid buffer capacity similar to that of sodium hypochlorite.

Materials and Methods AE was used at concentrations of $1 \%, 2 \%$, and $3 \%$. The bactericidal effect of AE on Enterococcus faecalis was evaluated by determining the colony number and biofilm removal rate. Biofilms were visualized using a Live/Dead BacLight bacterial viability kit. Viability of AE-treated cells were determined using a CCK-8 cell counting assay.

Statistical Analysis One-way analysis of variance followed by a Dunnett's multiple comparison test were used for comparisons among groups.

Results Significant reduction in cell viability and biofilm formation were observed in case of $3 \%$ and $2 \% \mathrm{AE}$. AE exerted bactericidal effects in a concentration-dependent manner. Damage of normal human fibroblasts was not observed at any of the $A E$ concentrations.

Conclusions Our results suggest that the AE solution could be used as an effective canal irrigant for the removal of bacterial biofilm.

\section{Introduction}

Endodontic treatment involves the removal of pulp infected with bacteria in case of dental caries and trauma to prevent apical periodontal disease. Additionally, it prevents reinfection of the root canal to avoid redundancy. The root canal is anatomically curved and narrow, exhibiting a complex structure with intricate branches at the apex, making it difficult for X-rays and imaging tools to diagnose root canal infections. ${ }^{1}$ The complexity of the root canal system makes it difficult to eliminate the source of infection. Recently, the development of cone beam computed tomography (CBCT) and optical coherence tomography (OCT) techniques have published online March 10, 2021
DOI https://doi.org/

10.1055/s-0041-1723067

ISSN 1305-7456. (c) 2021. European Journal of Dentistry.

This is an open access article published by Thieme under the terms of the Creative Commons Attribution-NonDerivative-NonCommercial-License, permitting copying and reproduction so long as the original work is given appropriate credit. Contents may not be used for commercial purposes, or adapted, remixed, transformed or built upon. (https://creativecommons.org/licenses/by-nc-nd/4.0/).

Thieme Medical and Scientific Publishers Pvt. Ltd. A-12, 2nd Floor, Sector 2, Noida-201301 UP, India 
made it possible to image the complex morphology of the root canal. Moreover, progress in the development of innovative therapeutic devices for endodontic treatment, such as rotary nickel titanium files, contributed to an effective and time-efficient means of shaping the canal. ${ }^{2}$ However, mechanical instrumentation alone does not prepare the entire root canal surface and is insufficient to remove bacteria, owing to the complexity of the root canal system..$^{1,3-5}$ Therefore, in addition to the mechanical cleaning, supplemental chemical cleaning with root canal irrigants is essential to achieve the desired prognosis in case of endodontics. ${ }^{6}$

Sodium hypochlorite $(\mathrm{NaOCl})$ is the most commonly used root canal irrigant, owing to its disinfecting capacity and its ability to disrupt biofilms and dissolve organic tissues. The lysing action of hypochlorous acid dissolves the pulp tissue and eradicates the residual bacteria in the root canal. It is necessary to effectively remove smear layers, smear plugs, and cutting debris attached to the root canal wall, which cannot be performed by mechanical cleaning alone. Therefore, ethylenediaminetetra-acetic acid (EDTA), which is capable of dissolving inorganic substances, is used in combination with another reagent in endodontic procedures. Therefore, the combination of chemical cleaning and mechanical cleaning leads to a successful root canal treatment.?

$\mathrm{NaOCl}$ exhibits an excellent organic-dissolving effect in root canal treatment; however, it could cause severe damage to the soft tissue if the solution scatters or leaks out of the apex. ${ }^{8}$ Cleaning agents are delivered to the apex of the root canal through the extra-articular area. This causes severe pain and acute inflammation, and in worse cases, it requires hospitalization owing to the high toxicity of $\mathrm{NaOCl}$ to vital tissues. ${ }^{9}$ Moreover, long-term exposure to EDTA could lead to root fractures or overdemineralization. Therefore, it is necessary to develop a root canal cleaning agent that is safe, easy to handle, and capable of exerting potent bactericidal effects.

In this study, we aimed to develop a method for safe and effective removal of both the organic matter and the smear layer by using a strong alkaline EDTA (AE) solution adjusted to the same acid buffer capacity as that of $\mathrm{NaOCl}$. The aim of this study was to evaluate the bactericidal effect and cytotoxicity of the root canal irrigation solution using EDTA solutions with different $\mathrm{pH}$ values to establish a next-generation root canal irrigation method.

\section{Materials and Methods}

\section{Bactericidal Effect}

Enterococcus faecalis (ATCC 19433) was cultured in brain heart infusion (BHI: Becton Dickinson and Company, Sparks, MD, USA) broth, supplemented with yeast extract $(5 \mathrm{mg} / \mathrm{mL})$ for 18 hours under anaerobic conditions $\left(\mathrm{CO}_{2}\right.$ : $\left.10 \%, \mathrm{H}_{2}: 10 \%, \mathrm{~N}_{2}: 80 \%\right)$ at $37^{\circ} \mathrm{C}$. A total volume of $10 \mu \mathrm{l}$ $\left(4.1 \times 10^{8}\right.$ colony-forming unit [CFU] $\left./ \mathrm{mL}\right)$ of bacterial suspension was treated with $1 \mathrm{~mL}$ of endodontic irrigants to determine their bactericidal effect. The effects of the following solutions of endodontic irrigants were investigated: Alkaline EDTA solution (AE: $0.09 \mathrm{~mol} / \mathrm{liter}$ EDTA) was adjusted to 1\%
(1\% AE, pH 11.9), 2\% (2\% AE, pH 12.1) and 3\% (3\% AE, pH 12.3), respectively; 3\% Smear clean (SC: pH 9.5, EDTA-2Na solution; Nippon Shika Yakuhin Co., Ltd, Yamaguchi, Japan), and 3\% Antiformin (AF: pH 12.3, NaOCl, Nippon Shika Yakuhin Co., Ltd). Phosphate-buffered saline (PBS: pH 7.5) was used for the control treatment. Following the treatment of bacterial cells with endodontic irrigants, 10 -fold serial dilution was performed using fresh BHI broth, and $100 \mu \mathrm{l}$ was then spread onto a BHI agar plate. Bactericidal effect was determined by evaluation of the number of CFU after 24 hours of incubation in anaerobic conditions. The experiment was performed in triplicate.

\section{Biofilm Removal Assay}

Bacterial biofilms were grown on sterilized coverslips for 18 hours. Following incubation, nonadherent cells were removed by washing with PBS, and E. faecalis biofilm was treated with various types of endodontic irrigants for 0 to 5 minutes to evaluate their biofilm removal effect. Biofilms were stained using the Live/Dead BacLight bacterial viability kit (Life Technologies; Eugene, OR, USA) and observed under a fluorescence microscope (BZ-X700; Keyence Corp., Osaka, Japan). The coverslips were stained with $1 \%$ crystal violet (CV). After CV staining, each coverslip was distained with $1 \mathrm{~mL}$ of $95 \%$ ethanol. Further, the optical density (OD) of CV-stained solution containing the biofilm was measured at $550 \mathrm{~nm}$ using a spectrophotometer (DU800; Beckman coulter, Brea, CA, USA). The experiment was performed in triplicate.

\section{Cell Survival Assay}

Human gingival fibroblasts (HGFs) were isolated from healthy gingival tissues of patients. The experimental procedures were approved by the Ethical Committee of Kanagawa Dental University (approval no. 455). HGFs were maintained in Dulbecco's modified Eagle's medium (DMEM; Nissui Pharmaceutical Co.; LTD, Tokyo, Japan) and supplemented with $0.35 \%$ glucose (FUJIFILM Wako Pure Chemical Corporation, Osaka, Japan), $0.28 \mathrm{mM}$ ascorbic acid (FUJIFILM Wako Pure Chemical Corporation), $4 \mathrm{mM}$ L-glutamine (Sigma-Aldrich; St. Louis, MO, USA), 0.18\% $\mathrm{NaHCO}_{3}$ (FUJIFILM Wako Pure Chemical Corporation), 50 $\mathrm{U} / \mathrm{mL}$ penicillin (Sigma-Aldrich), $50 \mu \mathrm{g} / \mathrm{mL}$ streptomycin (Sigma-Aldrich), and 10\% fetal bovine serum (FBS; S1820, Biowest, France), at $37^{\circ} \mathrm{C}$ under $5 \% \mathrm{CO}_{2}$. The medium was replaced every 2 days, and cells from passages 3 to 7 were cultured in 100-mm diameter cell culture dishes (Corning, NY, USA). Further, $1 \times 10^{4}$ cells were seeded onto a 96-well plate. Cell survival assay was measured using Cell Counting kit-8 (CCK-8; CK04-11, Dojindo, Kumamoto, Japan) at 30 second, 1 minute, 4 minutes, 5 minutes, and 10 minutes following the manufacturer's instruction. Cells were stained with $10 \mu \mathrm{l}$ of CCK-8 solution in each well and incubated at $5 \% \mathrm{CO}_{2}$ and $37^{\circ} \mathrm{C}$ for 4 hours. The OD values of each samples were then measured at $450 \mathrm{~nm}$ using a microplate reader (iMark microplate reader; Bio-Rad Laboratories, Inc., Hercules, CA, USA). This assay was performed in triplicate. 


\section{Statistical Analysis}

One-way analysis of variance (ANOVA) followed by a Dunnett's multiple comparison test were performed to analyze the results. Test results were considered significant when probability $(p)$ values were $<0.05$.

\section{Results}

The bacterial cells were treated with various endodontic irrigants. We observed that SC and 1\% AE did not exhibit any bactericidal effect, similar to PBS. However, hypochlorous acid exerted a significant bactericidal effect and reduced the number of viable $E$. faecalis cells after 1 minute of exposure. Additionally, 3\% AE reduced the viable E. faecalis count after 5 minutes of treatment, while $2 \% \mathrm{AE}$ significantly reduced the count of viable bacteria by half ( - Fig. 1). Our results demonstrated that AE inhibited the growth of floating bacteria in a concentration-dependent manner.

Further, we examined the bactericidal effect of various solutions on biofilm formation. We observed that $73.2 \%$ of the biofilm was removed following treatment with $3 \%$

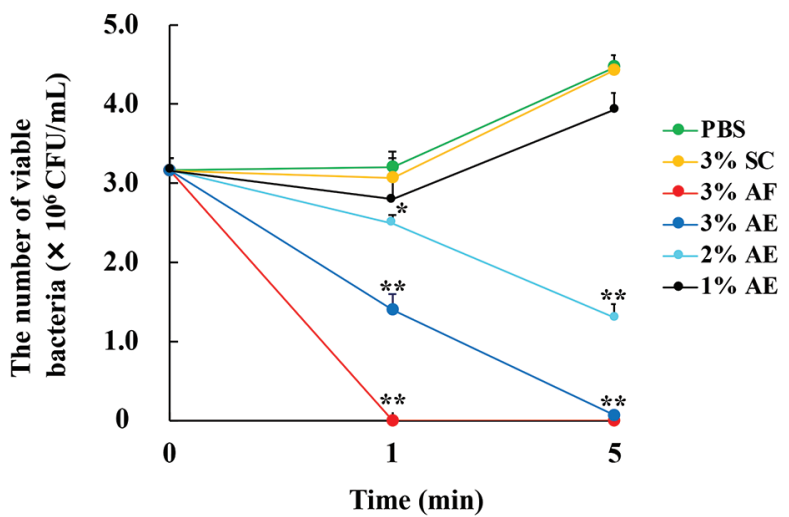

Fig. 1 Bactericidal effect of alkaline ethylenediaminetetra-acetic acid (EDTA) (AE). The number of viable bacteria after treatment with different concentrations of AE. ${ }^{*}: p<0.05,{ }^{* *}: p<0.01$.

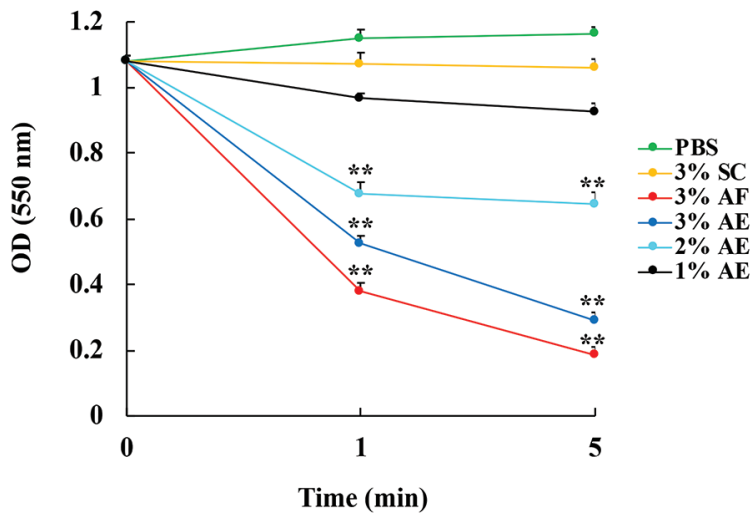

Fig. 2 Removal of E. faecalis biofilm. The percentage of biofilm removal after treatment with different concentrations of alkaline ethylenediaminetetra-acetic acid (EDTA) (AE). ${ }^{* *} p<0.01$
AE for 5 minutes (-Fig. 2). We also observed reduction in the number of bacterial cells after 1 minute of treatment ( - Fig. 3C), and lysis of bacteria was observed after 5 minutes ( - Fig. 3 I). On the contrary, SC and PBS only removed $1.9 \%$ of the biofilm after 5 minutes of treatment ( - Fig. 2). Besides, we did not observe any bactericidal effect in case of SC or PBS even after 5 minutes ( - Fig. 3G, 3H). On the other
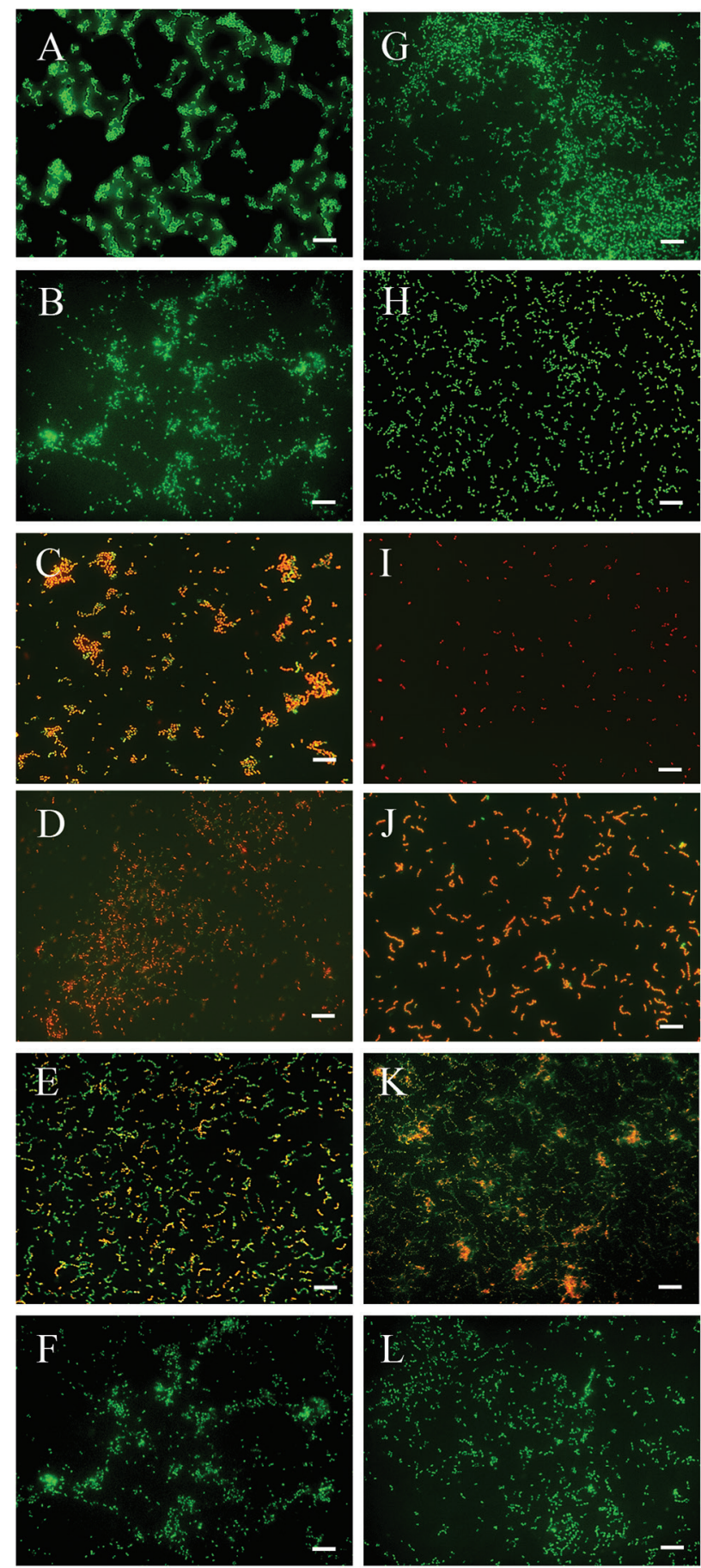

Fig. 3 Fluorescence microscopic images of E. faecalis biofilm stained using crystal violet (CV). The viable (green) and dead (red) bacteria are clearly visible. A,G; phosphate-buffered saline (PBS), $\mathrm{B}, \mathrm{H} ; 3 \%$ Smear clean (SC), C,I; 3\% Antiformin (AF), D,J; 3\% alkaline ethylenediaminetetra-acetic acid (EDTA) (AE), E,K; 2\% AE, F,L; 1\% AE, Bars: $10 \mu \mathrm{m}$. (bar; $x 100)$ 
hand, reduction in bacterial counts was observed in $\mathrm{AE}$ in a concentration-dependent manner (- Fig. 2), and most bacteria were killed upon treatment with $3 \% \mathrm{AE}$ for 5 minutes ( - Fig. $\mathbf{3} \mathrm{J}$ ). Therefore, $\mathrm{AE}$ is expected to be as effective as $\mathrm{AF}$ in the removal of biofilm.

Accidental escape of the cleaning fluid outside the apical foramen can occur during root canal cleaning. Therefore, it is necessary to consider the effect of the washing solution on the periodontal tissue of the root apex. Therefore, in this study, we aimed to investigate the effect of effective cleaning agents on human fibroblasts. We observed that most fibroblastic cells treated with AF were affected 4 minutes after the addition of $\mathrm{NaOCl}$ ( - Fig. 4). However, we did not observe any cell damage in case of AE, similar to that in the control.

\section{Discussion}

The success of endodontic treatment depends on the eradication of microbes from the root-canal system and prevention of the infection. The complex root canal morphology makes it difficult to eliminate $E$. faecalis, which penetrates dentinal tubules and forms biofilms. ${ }^{10,11}$ Surface adhesins and gelatinases of $E$. faecalis are involved in bacterial attachment, colonization, and biofilm formation. ${ }^{12,13}$ Therefore, it is essential to prevent secondary endodontic infections by eliminating this species from the root canal system. Refractory periapical periodontitis is complicated due to the presence of a biofilm formed by the bacterial flora near the apex. E. faecalis lipoteichoic acid (LTA) detected in refractory periapical periodontitis is thought to be one of the causes of the irreversible suppression of osteoblast proliferation and apoptosis via JAK2-STAT3 signaling. ${ }^{14,15} \mathrm{E}$. faecalis has been reported to be detected commonly by persistent endodontic infections. ${ }^{16}$ Therefore, we designed the bactericidal effects of alkalized EDTA on biofilms using E. faecalis. Our results suggest that alkalized EDTA could be used as an effective cleaning agent for the treatment of intractable root canals, as it suppresses the growth of $E$. faecalis.

Root canal lavage is one of the important requirements for determining the success or failure of the treatment that involves various cleaning agents. An ideal root canal cleaner

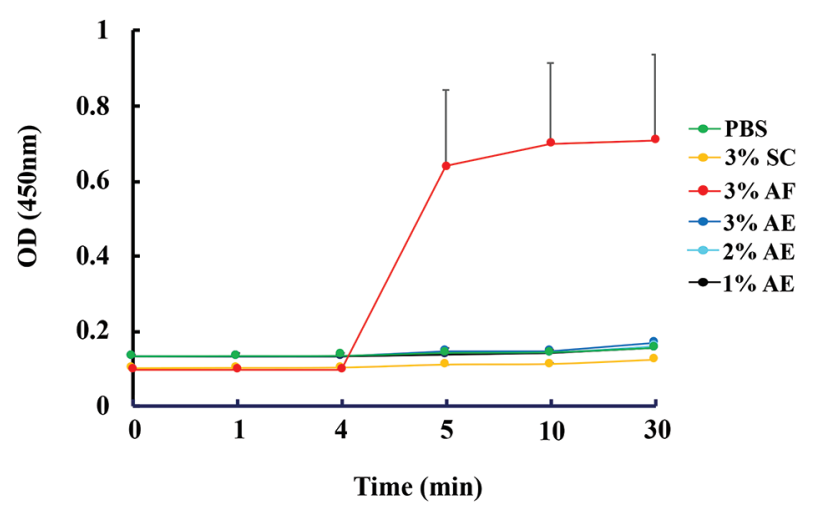

Fig. 4 Proliferation of cells treated with alkaline ethylenediaminetetraacetic acid (EDTA) (AE). The survival rate of human gingival fibroblast cells treated with $A E$. should efficiently remove debris, act as a lubricant to reduce friction due to the instrument during endodontic procedures and facilitate dentin removal, dissolve inorganic tissue and organic matter, kill bacteria and yeasts, inhibit biofilm production, avoid damage to vital periapical tissue, and prevent caustic or cytotoxic effects. ${ }^{6}$ There are no root canal cleaning agents that meet all of these requirements. EDTA, which is a cleaning solution, is mixed with hypochlorous acid or chlorhexidine, resulting in its precipitation and rendering it ineffective. ${ }^{6}$ On the other hand, EDTA Na4/NaOCl solution supplemented with the quaternary ammonium compound cetrimide does not interfere with the antibacterial activity of $\mathrm{NaOCl} .{ }^{17}$ Several studies have reported the development of hypochlorite solution that lacks chlorinated odor. ${ }^{18}$ Therefore, in this study, we aimed to develop an effective cleaning agent that reduced the unique scent and taste by using AE. ${ }^{19,20}$ Irrigation activation techniques have been proposed to improve their distribution through the canal system and enhance the antibacterial and antibiofilm capacity of root canal irrigants. ${ }^{21,22}$ However, since $\mathrm{NaOCl}$ has a high surface tension, the effect of penetrating dentinal tubules cannot be expected..$^{23}$ To exert an effective cleaning effect, the concentration and amount of agent used, and the effects of temperature on the interactions between agents, must be considered in combination to develop effective cleaning of the root canal. These findings suggest that further research is required to develop an appropriate cleaning method.

Root canal cleaning is effectively performed by appropriately supplying and stirring the cleaning agent into the root canal. ${ }^{24}$ Sonics ultrasonic, sonics photoactivation systems, and laser are widely used methods for irrigation activation that applies external mechanical force to the irrigants. ${ }^{24-26}$ Passive ultrasonic irrigation utilizes small noncutting files oscillating freely in shaped canals at ultrasonic frequencies, activating irrigates by acoustic streaming, whereas sonic irrigation produces a hydrodynamic phenomenon through oscillating movement by frequencies of 1 to $10 \mathrm{kHz}$. Laser-activated irrigation using Er:YAG laser has been introduced as an alternative method to activate root canal irrigation unique ability, in order to utilize micro-explosion to produce cavitation in the root canal agent by strong absorption of the laser energy. The combination of these cleaning methods could enhance their efficiency. Further studies should be performed using animal models of infected root canal to study the effect of the irrigant.

\section{Conclusions}

The AE solution promotes the inhibition of $E$. faecalis and effectively removes bacterial biofilms. These results indicate that the AE solution might have the potential to be applied as an endodontic irrigant in root canal treatment.

\section{Funding}

This work was supported by JSPS KAKENHI under grant numbers JP17K18193, JP16K11568, and JP18K09592.

\section{Conflict of Interest}

None declared. 


\section{References}

1 Siqueira JF, Jr., Araújo MC, Garcia PF, Fraga RC, Dantas CJ. Histological evaluation of the effectiveness of five instrumentation techniques for cleaning the apical third of root canals. J Endod 1997;23(8):499-502

2 Hülsmann M, Peters OA, Dummer PMH. Mechanical preparation of root canals: shaping goals, techniques and means. Endod Topics 2005;10(1):30-76

3 Peters OA, Schönenberger K, Laib A. Effects of four Ni-Ti preparation techniques on root canal geometry assessed by micro computed tomography. Int Endod J 2001;34(3):221-230

4 Peters OA, Peters CI, Schönenberger K, Barbakow F. ProTaper rotary root canal preparation: effects of canal anatomy on final shape analysed by micro CT. Int Endod J 2003;36(2):86-92

5 von Arx T. Frequency and type of canal isthmuses in first molars detected by endoscopic inspection during periradicular surgery. Int Endod J 2005;38(3):160-168

6 Haapasalo M, Shen Y, Qian W, Gao Y. Irrigation in endodontics. Dent Clin North Am 2010;54(2):291-312

7 Dioguardi M, Gioia GD, Illuzzi G, Laneve E, Cocco A, Troiano G. Endodontic irrigants: different methods to improve efficacy and related problems. Eur J Dent 2018;12(3):459-466

8 Hülsmann M, Hahn W. Complications during root canal irrigation-literature review and case reports. Int Endod J 2000;33(3):186-193

9 Guivarc'h M, Ordioni U, Ahmed HM, Cohen S, Catherine JH, Bukiet F. Sodium hypochlorite accident: a systematic review. J Endod 2017;43(1):16-24

10 Dioguardi M, Di Gioia G, Illuzzi G, et al. Inspection of the microbiota in endodontic lesions. Dent J (Basel) 2019;7(2):E47

11 Ran S, Gu S, Wang J, Zhu C, Liang J. Dentin tubule invasion by Enterococcus faecalis under stress conditions ex vivo. Eur J Oral Sci 2015;123(5):362-368

12 Barbosa-Ribeiro M, De-Jesus-Soares A, Zaia AA, Ferraz CC, Almeida JF, Gomes BP. Antimicrobial susceptibility and characterization of virulence genes of enterococcus faecalis isolates from teeth with failure of the endodontic treatment. J Endod 2016;42(7):1022-1028

13 Beomidehagh M, Rezaee MA, Ganbarov K, et al. Effect of acidic and alkali shocks on expression of efaA gene in Enterococcus faecalis, isolated from root canal infection. Cell Mol Biol 2018;64(13):1-5

14 Tian Y, Zhang X, Zhang K, et al. Effect of Enterococcus faecalis lipoteichoic acid on apoptosis in human osteoblast-like cells. J Endod 2013;39(5):632-637
15 Wang L, Jin H, Ao X, et al. JAK2-STAT3 signaling pathway is involved in rat periapical lesions induced by Enterococcus faecalis. Oral Dis 2019;25(7):1769-1779

16 Stuart CH, Schwartz SA, Beeson TJ, Owatz CB. Enterococcus faecalis: its role in root canal treatment failure and current concepts in retreatment. J Endod 2006;32(2):93-98

17 Solana C, Ruiz-Linares M, Baca P, Valderrama MJ, Arias-Moliz MT, Ferrer-Luque CM. Antibiofilm activity of sodium hypochlorite and alkaline tetrasodium EDTA solutions. J Endod 2017;43(12):2093-2096

18 Vajrabhaya LO, Sangalungkarn V, Srisatjaluk R, Korsuwannawong S, Phruksaniyom C. Hypochlorite solution for root canal irrigation that lacks a chlorinated odor. Eur J Dent 2017;11(2):221-225

19 Segu A, Bijukumar D, Trinh T, et al. Total eradication of bacterial infection in root canal treatment: an electrochemical approach. ACS Biomater Sci Eng 2018;4(7):2623-2632

20 Slaughter RJ, Watts M, Vale JA, Grieve JR, Schep LJ. The clinical toxicology of sodium hypochlorite. Clin Toxicol (Phila) 2019;57(5):303-311

21 De Moor RJ, Blanken J, Meire M, Verdaasdonk R. Laser induced explosive vapor and cavitation resulting in effective irrigation of the root canal. Part 2: evaluation of the efficacy. Lasers Surg Med 2009;41(7):520-523

22 Meire MA, Poelman D, De Moor RJ. Optical properties of root canal irrigants in the 300-3,000-nm wavelength region. Lasers Med Sci 2014;29(5):1557-1562

23 Giardino L, Del Fabbro M, Cesario F, Fernandes FS, Andrade FB. Antimicrobial effectiveness of combinations of oxidant and chelating agents in infected dentine: an ex vivo confocal laser scanning microscopy study. Int Endod J 2018;51(4):448-456

24 Gu LS, Kim JR, Ling J, Choi KK, Pashley DH, Tay FR. Review of contemporary irrigant agitation techniques and devices. J Endod 2009;35(6):791-804

25 van der Sluis LW, Versluis M, Wu MK, Wesselink PR. Passive ultrasonic irrigation of the root canal: a review of the literature. Int Endod J 2007;40(6):415-426

26 Virdee SS, Seymour DW, Farnell D, Bhamra G, Bhakta S. Efficacy of irrigant activation techniques in removing intracanal smear layer and debris from mature permanent teeth: a systematic review and meta-analysis. Int Endod J 2018;51(6):605-621 